\title{
More about the role of 2,6-dichlorophenol in tick courtship: identification and olfactometer bioassay in Amblyomma cajennense and Rhipicephalus sanguineus
}

\author{
Carla Cristina Braz Louly, Diana da Nóbrega Silveira, Sara Fernandes Soares, \\ Pedro Henrique Ferri' ${ }^{1}$, Ariane Carla Campos de Melo', Lígia Miranda Ferreira Borges²+ \\ Escola de Veterinária ${ }^{1}$ Instituto de Química ${ }^{2}$ Instituto de Patologia Tropical e Saúde Pública, Universidade Federal de Goiás, \\ Caixa Postal 131, 74001-970 Goiânia, GO, Brasil
}

\begin{abstract}
This study aimed to identify 2,6-dichlorophenol (2,6-DCP) in Amblyomma cajennense and to evaluate its role in A. cajennense and Rhipicephalus sanguineus courtship. Hexanic extract from attractive females was purified by solid phase extraction and the phenol was identified by the single ion monitoring method using GC/MS. In an olfactometer, the responses of $\mathrm{A}$. cajennense and $\mathrm{R}$. sanguineus males to females, control rubber septa or rubber septa impregnated with 2,6-DCP at 50, 500, and $5000 \mathrm{ng}$, respectively, were studied. 2,6-DCP was identified in A. cajennense extract and the males oriented themselves toward the concentration of $500 \mathrm{ng}$. These septa and the females were recognized as copula partners. The septa treated with 2,6-DCP did not attract and were not even recognized by the $\mathrm{R}$. sanguineus males, whereas the females were recognized. Due to the presence of 2,6-DCP in A. cajennense and the results of biological bioassays, it was concluded that this compound acts as an attractant and mounting sex pheromone in this tick, but it does not play any role in $\mathrm{R}$. sanguineus courtship.
\end{abstract}

Key words: 2,6-dichlorophenol - sex pheromone - Ixodidae - olfactometer bioassay - identification

Mate-finding and courtship behavior in ticks are largely regulated by pheromones. According to Sonenshine (1991), the hypothetical behavioral stages that occur during Dermacentor variabilis (Say) courtship can be described as follows. The feeding female secretes a volatile attractant sex pheromone, exciting the male to detach himself. The sexually excited male commences searching behavior, orients to the emitting source, and approaches the pheromone-secreting female. Male contacts the female, detects the mounting sex pheromone, mounts, turns and crawls over the female's opisthosoma to the ventral surface. The male locates the female's gonopore and following probing and successful identification of the genital sex pheromone, the spermatophore is formed and copulation ensues.

Since the pioneer studies identifying 2,6-dichlorophenol (2,6-DCP) as an attractant sex pheromone in Amblyomma americanum (Linnaeus) (Berger et al. 1971, Berger 1972) this same compound has been identified in 17 species of Ixodidae (Mayer \& Mclanglin 1991, Bruyne $\&$ Guerin 1994, Liu et al. 1998, Borges et al. 2002). Although identified in several species, confirmatory studies showing its role as an attractant sex pheromone were conclusive in seven species: D. variabilis, Dermacentor

Financial support: $\mathrm{CNPq}$

+ Corresponding author: ligia@iptsp.ufg.br

Received 28 August 2007

Accepted 11 February 2008 andersoni Stiles (Sonenshine et al. 1976), A. americanum, Amblyomma maculatum Koch (Kellum \& Berger 1977), Hyalomma dromedarii Koch, Hyalomma anatolicum excavatum Koch (Silverstein et al. 1983) and Dermacentor nitens Neumann (Borges et al. 2002). In $D$. variabilis, D. andersoni (Hamilton \& Sonenshine 1988) and $H$. dromedarii (Sobbhy et al. 1994), males attracted to 2,6-DCP placed on inanimate objects failed to recognize these objects as potential mates and left quickly even if they made physical contact with them. In these cases cholesteryl esters were necessary for the males to recognize the objects as sexual partners. Although this model is traditionally accepted, Borges et al. (2002) observed that $D$. nitens males are attracted, mount and proceed to ventral positioning on dummies impregnated with 2,6DCP. They concluded that in this species, 2,6-DCP acts as an attractant and mounting sex pheromone.

Rhipicephalus sanguineus (Latreille) and Amblyomma cajennense (Fabricius) are three-host species ticks widespread in Brazil. The main host of $R$. sanguineus is the dog which can suffer from babesiosis, erlichiosis, hepatozoonosis and mycoplasmosis, all transmitted by the tick (Woldehiwet \& Ristic 1993). This tick can also parasitize human beings (Dantas-Torres et al. 2006, Louly et al. 2006) and it is the vector of Rickettsia conorii in Europe and Rickettsia rickettsii in Arizona, USA (Woldehiwet \& Ristic 1993, Demma et al. 2005). A. cajennense especially parasitizes equids, but it may infest other mammals such as bovids, cervids, wild and domestic canids, birds and even man. In Brazil, A. cajennense is considered the main vector of $R$. rickettsii, the agent of Rocky Mountain spotted fever (Dias \& Martins 1939, Lemos et al. 1997, Horta et al. 2004, Guedes et al. 2005). 
Chow et al. (1975) identified 2,6-DCP in R. sanguineus female extract and observed that males responded to this compound by waving their legs, and detaching from the host, but attraction to this compound was not confirmed. Sobbhy et al. (1994) identified cholesteryl esters in $R$. sanguineus female extracts, but no bioassay was taken to confirm if these substances acted as mounting sex pheromone in this tick. Rechav et al. (1997) affirm that $A$. cajennense females do not emit sex pheromones and the production shifts to males, although no studies have been conducted for identification or attraction to 2,6-DCP. It is known that in this species the males produce a pheromone that induces males and females to attach. However, the aggregation of an individual on the host which occurs in other species of Amblyomma does not occur in $A$. cajennense. Thus, it is not known how the sexes would meet. This study was aimed to identify the presence of 2,6-DCP in A. cajennense females and to evaluate its role in A. cajennense and $R$. sanguineus courtship.

\section{MATERIALS AND METHODS}

Ticks - A. cajennense and R. sanguineus engorged nymphs were collected from infested horses and dogs, respectively, and incubated in constant conditions $\left(27^{\circ} \mathrm{C}\right.$, $\mathrm{RH}>80 \%, 24 \mathrm{~h}$ dark) until ecdysis. Then adults were fed on rabbits for six days to guarantee sexually mature males and females. The rabbits were infested with a maximum of 20 adults of $A$. cajennense and 30 of $R$. sanguineus. After one infestation with the first species and two or three with the second one, the rabbits were donated. During the infestations, the rabbits were clinically examined every day and showed no symptoms due to the tick parasitism.

Chemicals - Hexane, dichloromethane, ethyl acetate and methanol were Ultra-Resi Analysed grade (Mallinckrodt Baker, NJ, USA). Deionised water was purified through a MilliQ BioCell system from Millipore (Bedford, MA, USA). 2,6-DCP was the standard product (Sigma, St. Louis, USA). Membrane PVDF $(0.45 \mu \mathrm{m})$ Millex syringe filter units (Millipore) and an AccuBond ODS-C18 solid-phase extraction (SPE) column (100mg/ ml) (J\&W Scientific, Folsom, CA, USA) were mounted on a vacuum-filtration adapter (Aldrich).

Pheromone extraction - The pheromone was extracted by immersing 50 six-days fed $A$. cajennense females in $3 \mathrm{ml}$ of hexane and exposing them to ultrasound for 15 min. The suspension was filtered by a syringe filter and the solvent was evaporated under a nitrogen gas stream. One aliquot was dissolved in $1 \mathrm{ml}$ of methanol, poured into the AccuBond C18 SPE column and forced to pass through it at $1 \mathrm{ml} / \mathrm{min}$ by applying reduced pressure. The column had previously been activated and conditioned with $2 \mathrm{ml}$ of ethyl acetate, $2 \mathrm{ml}$ of methanol, and $2 \mathrm{ml}$ of deionized water to avoid drying out. After application of the sample, the column was dried by a stream of air for $10 \mathrm{~min}$. The analytes were then eluted with $4 \mathrm{ml}$ of ethyl acetate and the eluate was evaporated to dryness under a stream of nitrogen. The dry extract was reconstituted with hexane and $0.5 \mu \mathrm{l}$ of the extract was injected into the gas chromatograph.
Pheromone identification - The sample analyses were performed on a GC-MS Shimadzu QP5050A instrument under the following conditions: a CBP-5 (Shimadzu) fused silica capillary column (30 m long x $0.25 \mathrm{~mm}$ i.d. x $0.25 \mu \mathrm{m}$ film thickness composed of 5\% phenylmethylpolysiloxane) was connected to a quadrupole detector operating in full scan and in selective ion monitoring mode with electron impact ionization at $70 \mathrm{eV}$; the carrier gas was $\mathrm{He}(1 \mathrm{ml} / \mathrm{min} ; 56.7 \mathrm{kPa})$ in constant flow mode. Injector and interface temperatures were $250^{\circ} \mathrm{C}$ and $270^{\circ} \mathrm{C}$, respectively. Injections were in split mode with a split ratio of 1:5. The oven temperature was programmed as follows: the initial temperature was held for $1 \mathrm{~min}$ at $60^{\circ} \mathrm{C}$ and was then raised to $270^{\circ} \mathrm{C}$ at $40^{\circ} \mathrm{C} / \mathrm{min}$, and maintained for $3.75 \mathrm{~min}$ (total time of $10 \mathrm{~min}$ ). The ion-fragments $\mathrm{m} / \mathrm{z} 126\left[\mathrm{M}^{+}-\mathrm{Cl}_{2}\right], 162\left[\mathrm{M}^{+}\right], 164\left[\mathrm{M}^{+}+2\right]$ and $166\left[\mathrm{M}^{+}+4\right]$ were recorded for 2,6-DCP (retention time at $5.03 \mathrm{~min}$ ). Phenol identification was based on matching between the mass spectrum of the peak at retention time of 2,6-DCP in hexane extract and that of the authentic sample.

Olfactometer bioassay - The males were tested against different stimuli: sexually mature females, rubber septa treated with increasing concentrations $(50,500$ and $5000 \mathrm{ng}$ ) of 2,6-DCP diluted in hexane and septa treated with hexane (control). The septa were the size of a mature virgin female. In a glass arena olfactometer with the bottom covered with a grid paper $(1 \times 1 \mathrm{~cm})$ (Borges et al. 2002), the $A$. cajennense and $R$. sanguineus males were released individually at 5 and $2.5 \mathrm{~cm}$ respectively from the stimulus source. 15 to 20 males of each species were tested against each odor source. The females were attached to the paper by using a hypodermic needle. The total number of ticks (20 to 30 males) tested in one day were divided between the treatments. The grid paper was always changed along with the odor source. Before the beginning of an experimental day, the arena was cleaned using detergent, rinsed with distilled water, hexane and acetone. To avoid any interference of the observer in the behavior of the ticks, he stayed behind and around $30 \mathrm{~cm}$ from the arena, and followed the displacement of the tick on another grid paper $(3 \times 3 \mathrm{~cm})$. The percentages of males that oriented, showing directional movement toward the stimulus, and their tracks were recorded. The ticks' tracks were divided into sections, each of which was three times the length of the male tick. Two consecutive points were linked by a straight line and the angle was calculated between this line and the direction of the wind $\left(\right.$ angle $\left.0^{\circ}\right)$. The trajectories displayed by ticks were analyzed by means of circular statistics (Zar 1999). The mean angle displayed by each animal was calculated over the pathways they formed. Subsequently, for every experimental group a mean angle and the length of the resultant mean vector (r) was calculated and the statistical differences between groups were evaluated through the Watson $\mathrm{U}^{2}$ test. The percentage of males that recognized the odor source and proceeded to mounting and ventral positioning was also recorded. The ventral positioning was reached when some mounted males crawled over the septa, located themselves between the septa and the 
arena, and lifted the septa with the aid of their legs. The percentages of male ticks that oriented and mounted to different odor sources were recorded and compared using the Kruskal-Wallis test (Sampaio 1998). The significance level was $\mathrm{p}<0.05$ in both tests.

\section{RESULTS}

Pheromone identification - The retention time $\left(\mathrm{R}_{\mathrm{t}}=\right.$ $5.03 \mathrm{~min}$ ) and elution characteristics on the CBP5 column were determined for the authentic sample of 2,6-DCP (Fig. 1a). Observations of retention time and the characteristic cluster of peaks at 126,162,164, and $166 \mathrm{~m} / \mathrm{z}$ in the SPE-purified hexanic extract of attractive $A$. cajennense females were accepted as evidence that 2,6-DCP was present (Fig. 1b).

Olfactometer bioassay - The A cajennense males oriented toward 2,6-DCF at $500 \mathrm{ng}$ concentration. The septa with this concentration and the females were recognized by the males through mounting in $67 \%$ and $73 \%$ of cases respectively, and ventral positioning in $42 \%$ and $62.5 \%$ (Table). The displacement angles indicate that 2,6-DCP in all concentrations tested attracted the male ticks: more angles between $0^{\circ}$ and $10^{\circ}$ were observed in relation to the different odor sources (59\% to $80 \%)$ than in the control (47\%) (Fig. 2). No statistical differences were found among these groups $\left(0.044>\mathrm{U}^{2}>0.083\right)$ except between control and $500 \mathrm{ng}$ concentration $\left(\mathrm{U}^{2}=0.268\right)$. The percentage of $R$. sanguineus males that reached the different stimulus sources was similar for all odors tested, including the control (Table). The displacement angles also indicate that no source was attractive, because similar results were observed with the control (35\% of angles between $0^{\circ}$ and $10^{\circ}$ ) and the other stimuli (47 to $56 \%$ of angles between $0^{\circ}$ and $10^{\circ}$ ) (Fig. 3) and no statistical differences were found among these groups $\left(0.031>\mathrm{U}^{2}>0.083\right)$. The septa treated with 2,6-DCP were not recognized by the males as mounting behavior did not occur, but $42 \%$ of the males that reached the females mounted and $20 \%$ of them proceeded to ventral positioning (Table).

\section{DISCUSSION}

In the present study we add $A$. cajennense to the extensive list of ticks that produce 2,6-DCP (Mayer \& Mclanglin 1991, Bruyne \& Guerin 1994, Liu et al. 1998, Borges et al. 2002). Leahy and Booth (1976) presumed that 2,6DCP was a sex pheromone of A. cajennense, based on the aggregation of male ticks in a Petri dish arena treated with
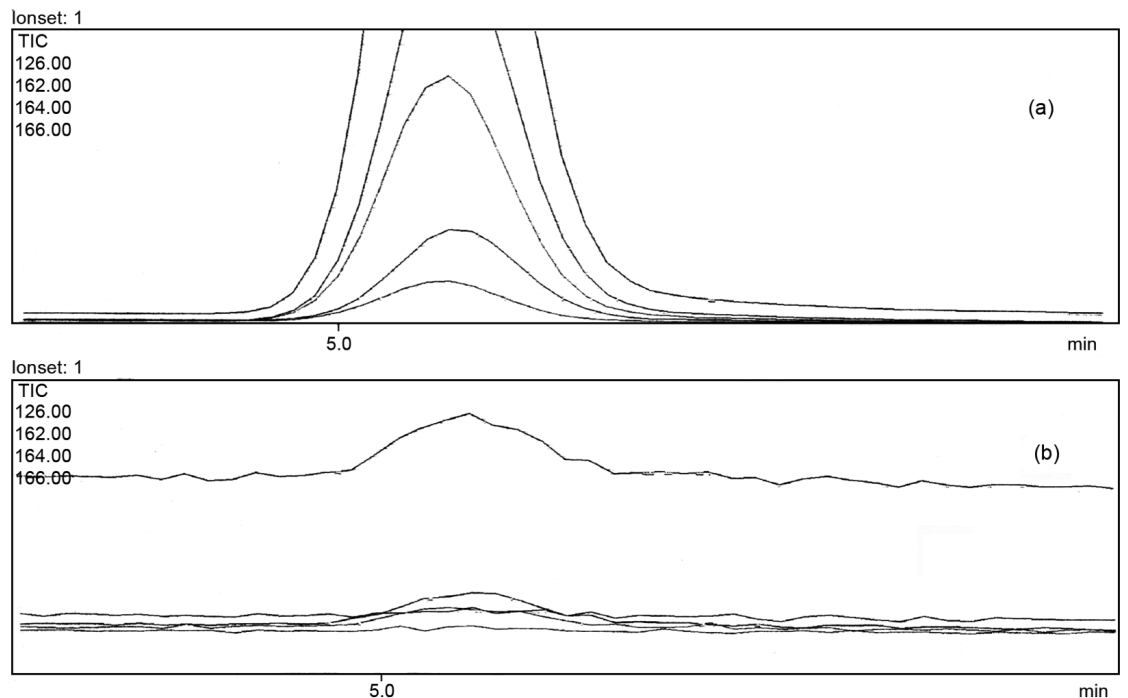

Fig. 1: total ion chromatogram (TIC) of authentic samples of 2,6-dichlorophenol (2,6-DCP) (a) and of the SPE-purified hexane extract of Amblyomma cajennense showing the 2,6-DCP in retention time at $5.03 \mathrm{~min}$ (b). Numerical value refers to monitored ion-fragments.

TABLE

Percentage of orientation (O), mount (M) and ventral positioning (VP) of the odor source by males of Rhipicephalus sanguineus and Amblyomma cajennense when exposed to different stimulus, in an olfactometer

\begin{tabular}{|c|c|c|c|c|c|c|}
\hline \multirow[b]{2}{*}{ Odor source } & \multicolumn{3}{|c|}{ R. sanguineus } & \multicolumn{3}{|c|}{ A. cajennense } \\
\hline & Orientation & Mount & Ventral positioning & Orientation & Mount & Ventral positioning \\
\hline Control & $35^{a}$ & $0^{a}$ & - & $30^{a}$ & $0^{a}$ & - \\
\hline Female & $60^{a}$ & $42^{b}$ & 20 & $55^{a}$ & $73^{b}$ & 62.5 \\
\hline $50 \mathrm{ng}$ 2,6-DCP & $60^{a}$ & $0^{a}$ & - & $53^{a}$ & $0^{a}$ & - \\
\hline 500 ng 2,6-DCP & $60^{a}$ & $0^{a}$ & - & $90^{b}$ & $67^{b}$ & 42 \\
\hline 5000 ng 2,6-DCP & $60^{a}$ & $17^{a}$ & 0 & $47^{a}$ & $0^{a}$ & - \\
\hline
\end{tabular}

$a, b$ : different letters within the same column indicate significant differences by Kruskal-Wallis test $(\mathrm{p}<0.05)$. 

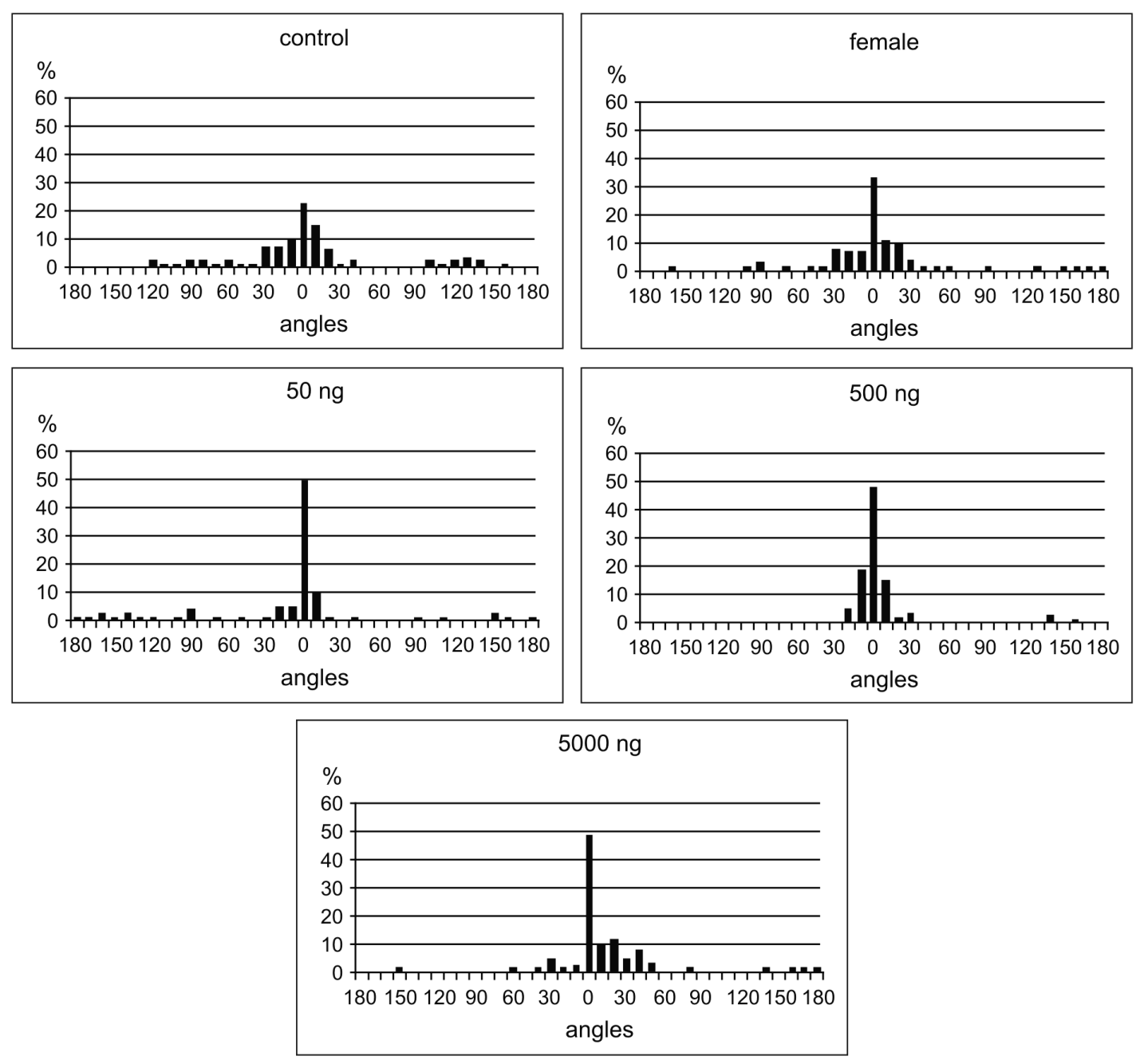

Fig. 2: frequencies of displacement angles of Amblyomma cajennense males to different odor sources in an olfactometer bioassay.

that compound; however, no attempt was made to identify the presence of the phenol in tick extracts.

When developing bioassays to evaluate the activity of pheromones or possible pheromones, the methodology must allow the expression of the characteristic behavior believed to be regulated by the pheromone (Sonenshine 1991). The present olfactometer bioassay allows the observation of the attraction, orientation and recognition of the odor source. The first two behaviors are regulated by an attractant sex pheromone and the last one by a mounting sex pheromone. When we used that bioassay for the first time (Borges et al. 2002) we did not expect to observe mounting of the rubber septa treated with 2,6-DCP as that behavior is traditionally guided by cholesteryl esters (Hamilton et al. 1989, Sobbhy et al. 1994). However, the observation of this unusual behavior stimulated us to evaluate the same bioassay with other tick species.

In $A$. cajennense the attraction and recognition (mounting and ventral positioning) of the septa impregnated with 2,6-DCP suggest that this compound acts as an attractant and mounting sex pheromone of this tick. Rechav et al. (1997) say that A. cajennense females do not produce sexual pheromones. In the genus Amblyom$m a$ the presence of aggregation-attachment pheromone produced by fed males has been widely reported (Sonenshine 1991). As demonstrated by Rechav et al. (1997), the males of $A$. cajennense produce a pheromone which promotes the attachment of unfed males and females, but not their aggregation. Given these points, how would the sexes meet in this species? The results obtained here suggest that courtship in $A$. cajennense occurs in the same way as in D. nitens (Borges et al. 2002), but is different from what was observed in D. variabilis, D. andersoni (Hamilton et al. 1989) and H. dromedarii (Sobbhy et al. 1994). Males of those last species were attracted to 2,6DCP which was placed on inanimate objects but failed to recognize them as potential mates and needed cholesteryl esters as a cue for that. It is possible that compounds playing a role as mounting sex pheromones, such as cholesteryl esters strengthen the response of 2,6-DCP in A. cajennense, but further studies are needed to address this question.

The septa treated with 2,6-DCP did not attract and was not even recognized by the males of $R$. sanguineus. For this reason, it is probable that 2,6-DCP does not act 

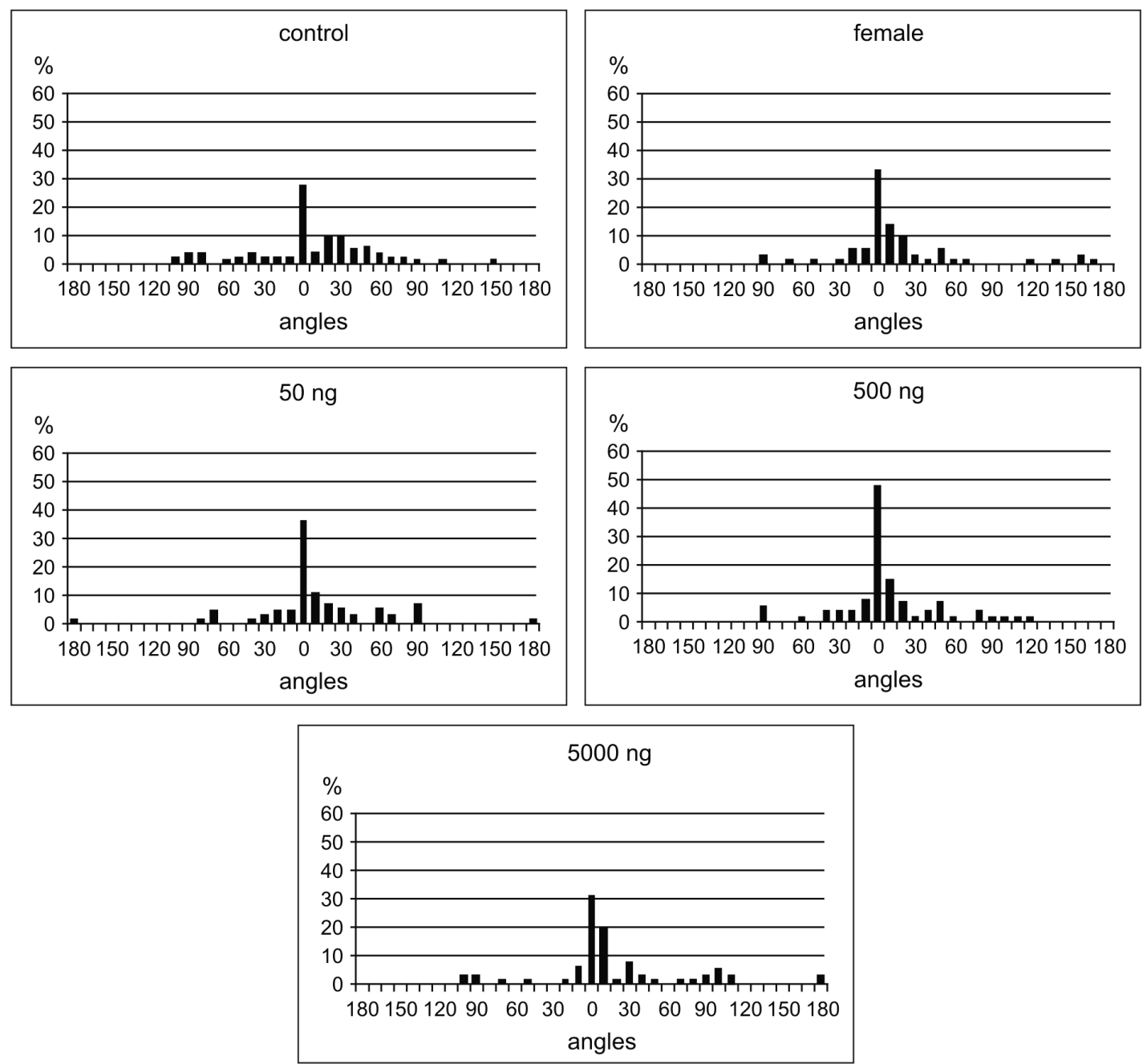

Fig. 3: frequencies of angles of Rhipicephalus sanguineus males to different odor sources in an olfactometer bioassay.

as an attractant or mounting sex pheromone in this tick. The non attractiveness of this compound is uncommon among metastriate Ixodidae, since several authors have reported its role as an attractant sex pheromone (Sonenshine et al. 1976, Kellum \& Berger 1977, Silverstein et al. 1983, Borges et al. 2002). Bruyne and Guerin (1994) did not observe a behavioral response of Rhipicephalus microplus (Canestrini) males to 2,6-DCP. However, Cardoso et al. (2000) observed a little attraction to this compound, suggesting that physiological differences among the ticks used in the different assays would be responsible for the different behavioral responses. On the other hand, the non recognition of the septa treated with 2,6-DCP is more common and has already been reported in D. variabilis, D. andersoni (Hamilton \& Sonenshine 1988) and H. dromedarii (Sobbhy et al. 1994).

The higher orientation responses of $A$. cajennense to impregnated 2,6-DCP septa at $500 \mathrm{ng}$ concentration in comparison to females probably occurred because the concentrations tested were higher than those released by females. The maximum amount of 2,6-DCP detected in Amblyomma females is around $65 \mathrm{ng}$ (Kellum \& Berger
1977), therefore justifying the results. The decreasing responses to the highest concentration may have occurred because of the saturation of tick receptors.

Borges et al. (2006) tried to associate the aspect of the female dorsal fovea of four species of Ixodidae with the role of 2,6-DCP in their courtship. Based on fovea aspects the ticks were divided in two groups, with $(D$. nitens and $A$. cajennense) and without ( $R$. microplus and $R$. sanguineus) secretions on the fovea. At that time it was known from the literature that 2,6-DCP played a role as a mounting sex pheromone in D. nitens (Borges et al. 2002), but not in R. microplus (Bruyne \& Guerin 1994, Cardoso et al. 2000). For this reason, they hypothesized that 2,6-DCP would be a mounting sex pheromone in $A$. cajennense but not in $R$. sanguineus. Thus, the results of the bioassays described here corroborate the hypothesis suggested in that study.

2,6-DCP has previously been shown to control metastriate ixodid ticks by confounding males or mimicking females (Ziv et al. 1981, Sonenshine et al. 1985, AbdelRahman et al. 1998, Sonenshine 2006, Borges et al. 2007). Considering the results obtained here, it is reasonable to 
suggest the use of this compound to intercept $A$. cajennense courtship; however its use in $R$. sanguineus is not recommended because it is not an attractant for this species of tick.

\section{REFERENCES}

Abdel-Rahman MS, Fahmy MM, Aggour M 1998. Trials for control of ixodid ticks using pheromone acaricide tick decoys. J Egypt Soc Parasitol 28: 551-557.

Berger RS 1972. 2,6-Dichlorophenol, sex pheromone of the lone star tick. Science 177: 704-705.

Berger RS, Dukes JC, Chow YS 1971. Demonstration of a sex pheromone in three species of hard ticks. J Med Entomol 8: 84-86.

Borges LMF, Eiras AE, Ferri PH, Lobo ACC 2002. The role of 2.6dichlorophenol as sex pheromone of the tropical horse tick Anocentor nitens (Acari: Ixodidae). Exp Appl Acarol 27: 223-230.

Borges LMF, Ferreira LAM, Schneider LS, Oliveira RA, Mussi SV, Faria KA, Melo LS, Abud LJ, Costa GL, Soares SF 2007. Efficacy of 2,6-dichlorophenol lure to control Dermacentor nitens. Vet Parasitol 147: 155-160.

Borges LMF, Ribeiro MFB, Bicalho KA, Ferreira F 2006. Estudo das fóveas dorsais de ninfas e adultos de quatro espécies de carrapatos (Acari: Ixodidae) por microscopia eletrônica de varredura. Rev Bras Parasitol Vet 15: 89-96.

Bruyne M, Guerin PM 1994. Isolation of 2,6-dihlorophenol from the cattle tick Boophilus microplus: receptor cell responses but not evidence for a behavioral response. J Insect Physiol 40: 143-154.

Cardoso VA, Borges LMF, Eiras AE 2000. 2,6-dichlorophenol as attractant sex pheromone of Boophilus microplus (Acari: Ixodidae). In 17th Annual Meeting of the International Society of Chemical Ecology, Poços de Caldas, p. PO43.

Chow YS, Wang CB, Lin LC 1975. Identification of a sex pheromone of the female brown dog tick, Rhipicephalus sanguineus. Ann Entomol Soc Am 68: 485-488.

Dantas-Torres F, Figueredo LA, Brandão-Filho SP. 2006. Rhipicephalus sanguineus (Acari: Ixodidae), the brown dog tick, parasitizing humans in Brazil. Rev Soc Bras Med Trop 39: 64-67.

Demma LJ, Traeger MS, Nicholson WL, Paddock CD, Blau DM, Eremeeva ME, Dasch GA, Levin ML, Singleton JJr, Zaki SR, Cheek JE, Swerdlow DL, Mcquiston JH. 2005. Rocky mountain spotted fever from an unexpected tick vector in Arizona. $N$ Engl $J$ Med 353: 587-594.

Dias E, Martins AV 1939. Spotted fever in Brazil. A summary. Am J Trop Med Hyg. 19: 103-108.

Guedes E, Leite RC, Prata MCA, Pacheco RCP, Walker DH, Labruna MB 2005. Detection of Rickettsia rickettsii in Amblyomma cajennense in a new Brazilian spotted fever-endemic area in the state of Minas Gerais. Mem Inst Oswaldo Cruz 100: 841-845.

Hamilton JGC, Sonenshine DE 1988. Evidence for the occurrence of mounting sex pheromone on the body surface of female Dermacentor variabilis (Say) (Acari: Ixodidae). J Chem Ecol 14: 401-410.

Hamilton JGC, Sonenshine DE, Lusby WR 1989. Cholesteryl oleate: mounting sex pheromone of the hard tick Dermacentor variabilis (Say) (Acari: Ixodídae). J Insect Physiol 11: 873-879.

Horta M, Labruna MB, Sangioni LA, Vianna MCB, Gennari SM, Galvão MAM, Mafra CL, Vidotto O, Schumaker TTS, Walker DH 2004. Prevalence of antibodies to spotted fever group rickettsiae in humans and domestic animals in a Brazilian spotted fever-endemic area in the state of São Paulo, Brazil: serologic evidence for infection by Rickettsia rickettsii and another spotted fever group rickettsia. Am J Trop Med Hyg 71: 93-97.

Kellum D, Berger RS 1977. Relationship of the occurrence and function of 2,6-dichlorophenol in two species of Amblyomma (Acari: Ixodidae). $\mathrm{J}$ Med Entomol 20: 701-705.

Leahy MG, Booth KS 1976. Perception of a sex pheromone, 2,6-dichlorophenol, in hard ticks. In JKH Wilde, Tick-borne Diseases and their Vectors, Ed. Proc Ind Conf Centre Trop Vet Med, Edinburgh University Press, Scotland, p. 88 .

Lemos ERS, Machado RD, Pires FDA, Machado SL, Costa LMC 1997. Rickettsiae-infected ticks in an endemic area of spotted fever in the State of Minas Gerais, Brazil. Mem Inst Oswaldo Cruz 92: 477-481.

Liu JZ, Jiang ZJ, Yang YP, Sun RY 1998. Quantitative variation of the sex pheromone, 2, 6-dichlorophenol, of Haemaphysalis longicornis (Acari: Ixodidae), and its role in biology. Acta Parasitol Med Entomol Sin 5: 253-257.

Louly CCB, Fonseca IN, Oliveira VF, Borges, LMF 2006. Ocorrência de Rhipicephalus sanguineus em trabalhadores de clínicas veterinárias e canis, no município de Goiânia, GO. Cien Anim Bras 7: 103-106.

Mayer MS, Mclanglin JR 1991. Handbook of insect pheromones and sex attractants, CRC Press, Boca Raton, 1083 pp.

Rechav Y, Goldberg M, Fielden LJ 1997. Evidence for attachment pheromones in the cayenne tick (Acari: Ixodidae). J Med Entomol 34: $234-237$

Sampaio IVB 1998. Estatística aplicada à experimentação animal, Fundação de Ensino e Pesquisa em Medicina Veterinária, Belo Horizonte, $221 \mathrm{pp}$

Silverstein R, West JR, Khalil GM, Sonenshine DE 1983. Occurrence of 2,6-dichorophenol in the hard ticks Hyalomma dromedarii and Hyalomma anatolicum excavatum with note on its role in mating regulation in these species. J Chem Ecol 9: 1543-4549.

Sobbhy H, Aggour MG, Sonenshine DE, Burridge MJ 1994. Cholesteryl esters on the body surfaces of the camel tick, Hyalomma dromedarii (Koch, 1844) and the brown dog tick, Rhipicephalus sanguineus (Latreille, 1806). Exp Appl Acarol 18: 265-280.

Sonenshine DE 1991. Biology of ticks, Vol. 1, Oxford Univ. Press, New York, 119 pp.

Sonenshine DE 2006. Tick pheromones and their use in tick control. Ann Rev Entomol 51: 557-580.

Sonenshine DE, Silverstein RM, Plummer E, West JR, McCullough T. 1976. 2,6-dihlorophenol, the sex pheromone of the Rocky Mountain wood tick, Dermacentor andersoni Stiles and the American dog tick, Dermacentor variabilis (Say). J Chem Ecol 2: 201-209.

Sonenshine DE, Taylor D, Corrigan G 1985. Studies to evaluate the effectiveness of sex pheromone-impregnated formulations for control of populations of the American dog tick, Dermacentor variabilis (Say) (Acari: Ixodidae). Exp Appl Acarol 1: 23-34.

Woldehiwet Z, Ristic M 1993. Rickettsial and Chlamydial diseases of domestic animals, Pergamon, Oxford, 427 pp.

Zar JH 1999. Biostatistical Analysis. 4th ed., Prentice Hall, New Jersey, $x i i+663 p p$.

Ziv M, Sonenshine DE, Silverstein RM, West JR, Gingher KH 1981. Use of sex pheromone, 2.6-dichlorophenol, to disrupt mating by American dog tick, Dermacentor variabilis (Say). J Chem Ecol 7: 829-840. 